\title{
Fundo público e políticas sociais no capitalismo: considerações teóricas ${ }^{1}$
}

\section{Public fund and social policies in capitalism: theoretical considerations}

\author{
Rodrigo de Souza Filho \\ Doutor em Serviço Social/UFRJ, professor associado da Faculdade de Serviço Social/UFJF, Juiz de Fora (MG), Brasil. \\ rodrigosfilho@ig.com.br
}

Resumo: O artigo analisa teoricamente a dinâmica de acumulação capitalista e a estrutura do fundo público a partir da reflexão marxiana sobre a distribuição da renda e a repartição do valor. Indica que, devido à expansão da intervenção do Estado na sociedade, o processo de disputa da riqueza socialmente produzida, mediada pelo fundo público, ganha um contorno qualitativamente diferenciado. Neste sentido, reflete sobre o significado do antivalor e sua relação com o desenvolvimento das políticas sociais.

Palavras-chave: Repartição do valor. Fundo público. Políticas sociais.
Abstract: In this article it is theoretically analyzed the dynamic of the capitalist accumulation and the structure of the public fund from the Marxian reflection about income and value distribution. It shows that, because of the expansion of the State intervention in society, the process of socially produced wealth dispute, mediated by the public fund, gets a qualitatively different contour. In this sense the meaning of anti-value and its relation with the development of social policies is reflected about.

Keywords: Value distribution. Public fund. Social policies.

\section{Apresentaçãa $0^{1}$}

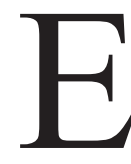
ste artigo, do ponto de visto político, se alinha ao entendimento de que "a defesa das políticas sociais universais e gratuitas e dos direitos sociais materializados por elas [se enquadra] na agenda anticapitalista, como mecanismos de transição e de reprodução da força de trabalho

1. Este artigo é produto do estágio pós-doutoral realizado com recursos da Capes — Processo BEX 7327/14-5, realizado no Departamento de Relaciones Sociales da Universidad Autónoma Metropolitana - Xochimilco, México, sob a supervisão do prof. dr. Jaime Osorio, no período de fevereiro de 2015 a agosto de 2015. 
centrais nesse momento histórico, e como disputa do destino do fundo público [...]". (Behring, 2012, p. 154)

Para evitar qualquer tipo de dúvida em relação à perspectiva aqui adotada, não estamos advogando que a ação no campo das políticas sociais seja "o" caminho da revolução. Apenas indicamos que é um ponto importante da agenda anticapitalista e que pode contribuir efetivamente com o acirramento das contradições da ordem do capital, além de atender de forma imediata às necessidades e demandas da classe trabalhadora. Mesmo porque, não podemos esquecer que o Estado - enquanto instituição que tem como função a preservação da ordem social e política do capital — "é por natureza totalmente incapaz de conceber, para não dizer efetivar, qualquer alteração da ordem social vigente" (Mandel, 1982, p. 348).

A partir dessa perspectiva, busca-se considerar os elementos teórico-metodológicos que consideramos fundamentais para a análise da dinâmica da acumulação capitalista e da estrutura do fundo público, a partir da reflexão marxiana sobre a distribuição da renda e a repartição do valor.

Para atingir tal objetivo, este artigo, além desta breve apresentação, possui uma primeira parte que trata de questões metodológicas que consideramos cruciais para um efetivo trabalho de pesquisa no campo das políticas sociais de Estados dependentes. Em seguida, trabalhamos a categoria repartição do valor em sua articulação com a questão do fundo público. $\mathrm{O}$ terceiro item procura avançar no debate sobre o fundo público no capitalismo tardio e sua relação com as políticas sociais, para, à guisa de conclusão, indicarmos a hipótese da configuração do fundo público na América Latina.

\section{Considerações teórico-metodológicas}

O presente trabalho concentra seus esforços em decodificar de forma mais precisa o momento econômico da dinâmica da acumulação capitalista para contribuir com as análises sobre as políticas sociais. Assim, ocupa-se, centralmente, da dimensão objetiva do tema, que se configura como o elemento estrutural por excelência, no qual age, constitutiva e permanentemente, 
a dinâmica subjetiva das lutas de classes, do poder do Estado e de sua institucionalidade. Portanto, o trabalho proposto, embora inserido na perspectiva crítico-dialética, tem como objeto central a dimensão objetiva da temática. Assim, configura-se como um enfoque parcial para a compreensão da totalidade do fenômeno das políticas sociais.

Essa opção também se alinha à compreensão de que é a partir da dinâmica das relações sociais de produção que melhor podemos caracterizar e analisar as dinâmicas das lutas entre classes, frações e setores (Osório, 2012), identificando de forma mais precisa as possibilidades, limites e perspectivas da intervenção social do ponto de vista do trabalho. A ação efetiva das classes/frações/setores está ancorada nas condições objetivas existentes. Portanto, as alternativas não são ilimitadas, mas também não está determinada apenas uma possibilidade de atuação. Neste quadro, identificar as táticas e estratégias mais adequadas de intervenção, do ponto de vista do trabalho, para cada momento histórico, torna-se uma tarefa teórico-política de primeira ordem. Não esquecendo, obviamente, que a intervenção definida a partir das condições objetivas sofrerá o impacto de outras intervenções subjetivas pautadas em interesses divergentes e antagônicos àqueles perspectivados pelo trabalho. O resultado desse processo, portanto, não se encontra predefinido.

Seguindo essa trilha, para analisar a dimensão objetiva das políticas sociais na América Latina, entendemos que devemos tratar a dinâmica do modo de produção capitalista, o capitalismo dependente, o padrão de reprodução do capital, a política econômica e a estrutura da política social enquanto determinações que interagem dialeticamente. Assim, vejamos de forma breve cada uma dessas determinações.

A primeira dimensão a ser destacada, mais ampla e abstrata, refere-se à dinâmica do modo de produção capitalista e, inserida nesse marco, a função e os limites da política social no complexo processo de produção e reprodução das relações sociais capitalistas.

Sumariamente, podemos indicar que enquanto função, as políticas sociais atendem de forma direta a necessidade de reprodução da força de trabalho (educação, saúde, lazer, moradia, transporte, entre outras), atuando, 
assim, como salário indireto. Simultaneamente, contribuem para a reprodução do capital, na medida em que criam uma série de demandas materiais que serão adquiridas pelo fundo público, junto às empresas capitalistas, para a efetivação dos bens e serviços sociais. Outro aspecto refere-se à contribuição para que os produtores de mercadorias possam também assumir de forma mais ativa a função de consumidores das mercadorias produzidas. Dessa forma, a intervenção social do Estado capitalista faz parte dos esforços necessários para "proporcionar uma base material adequada à escala ampliada do Estado do capital monopolista" (Mandel, 1982, p. 339). Entretanto, cabe ressaltar que a elevação do salário para além do seu valor encontra limites na própria dinâmica da acumulação capitalista.

A segunda determinação refere-se, num nível mais concreto, à particularidade do capitalismo dependente e suas implicações para a funcionalidade e os limites de desenvolvimento das políticas sociais nos países periféricos.

Sinteticamente, o quadro da dependência, conforme tratado por Marini (2005), implica a existência de uma dinâmica estrutural baseada na superexploração da força de trabalho (violação do valor da força de trabalho) como forma de operar a acumulação capitalista dependente, viabilizando simultaneamente a inserção da América Latina na economia mundial - através da venda de alimentos e matérias-primas para os países centrais, contribuindo, assim, com o deslocamento da acumulação via mais-valia absoluta para a mais-valia relativa desses países - e de compensar a deterioração dos termos de troca (transferência de valor) existente entre os bens salário e matérias-primas em relação aos produtos manufaturados para viabilizar a acumulação interna.

O resultado da dinâmica da superexploração decorrente da transferência de parte do mais valor produzido nos países dependentes para os países centrais para o desenvolvimento de políticas sociais é duplamente perverso. Por um lado temos a redução das condições objetivas de destinação de recursos do fundo público, necessários para a expansão dos direitos sociais. Por outro lado, a dinâmica da violação do valor da força de trabalho 
deteriora as condições de vida da classe trabalhadora de maneira substantiva, ampliando as necessidades para a reprodução social do trabalhador.

Dessa forma, mesmo num quadro de luta de classes mais favorável à classe trabalhadora, há uma possibilidade mais reduzida para a alocação de recursos públicos para as políticas sociais em comparação com uma dinâmica não dependente.

A determinação seguinte diz respeito à análise do padrão de reprodução do capital que se conforma em cada período histórico concreto.

A formulação do padrão de reprodução do capital enquanto categoria de análise da dinâmica de acumulação do capital, desenvolvida por Osório (2012), parte das reflexões de Marini sobre o ciclo do capital (2012 [1979]) e sobre o padrão de reprodução do capital no Chile (1982).

O padrão de reprodução do capital pode ser entendido como um campo de mediações que permite articular as dimensões mais gerais/abstratas da análise (modo de produção capitalista e sistema mundial) com as dimensões mais concretas e históricas (formação social e conjuntura) do desenvolvimento capitalista de determinada nação/região, tendo como elemento condutor a análise do ciclo do capital (Osório, 2012).

Dessa forma, os limites estruturais para o desenvolvimento das políticas sociais na América Latina devem ser entendidos não apenas de forma geral, a partir da análise do capitalismo dependente, mas também pelos períodos que demarcam padrões de reprodução do capital distintos, o que implica relacionar esses padrões com o Estado, com a luta de classes e com a dinâmica do fundo público de forma mais concreta.

A política econômica adotada para manter ou alterar determinado padrão de reprodução do capital conforma-se com a quarta determinação a ser considerada no âmbito da análise objetiva das políticas sociais. No desenrolar de determinado padrão de reprodução do capital, diferentes políticas econômicas podem ser implementadas e estas impactarão de forma distinta os recursos para as políticas sociais e a distribuição de renda e riqueza. Dessa forma, a política econômica pode, dentro de certo padrão de reprodução, oferecer mais ou menos possibilidades para o desenvolvimento de 
políticas sociais. Sem dúvida, algumas políticas econômicas são mais ou menos adequadas a determinado padrão de reprodução do capital. Fortalecer uma política econômica mais favorável ao desenvolvimento de políticas sociais universais pode contribuir para a alteração de um padrão de reprodução do capital mais restritivo aos interesses do trabalho.

Determinado padrão de reprodução do capital implica certa estrutura de política econômica para viabilizar sua manutenção/repetição/perpetuação, assim como, para sua superação, há necessidade de outra estrutura de política econômica (Osório, 2009).

Por fim, devemos considerar como dimensão mais concreta a própria estrutura da política social efetivada. Esta não é decorrente de forma direta e imediata da política econômica, do padrão de reprodução do capital ou da dinâmica de dependência do capitalismo latino-americano. Esses elementos impõem restrições a seu desenvolvimento, cujo elemento central encontra-se na lógica da dependência pautada na superexploração da força de trabalho. No entanto, a partir desse limite mais determinante pode existir um padrão de reprodução do capital mais favorável aos interesses da classe trabalhadora, além de políticas econômicas que fortaleçam essa direção. No entanto, a estrutura e lógica da política social implementada pode ser restritiva, não fundada em direitos de cidadania e dever do Estado. Por isso, além dos limites impostos pela dinâmica da dependência, padrão de reprodução e política econômica para o desenvolvimento das políticas sociais, é fundamental analisar a própria estrutura da política social existente formal e legalmente e sua efetiva implementação.

Enfim, considerando, portanto, que o salário total do trabalhador incorpora o salário indireto, reiteramos a possibilidade de que a expansão das políticas sociais efetivadas pelo Estado, através do fundo público, pode contribuir para o movimento de tensionamento na acumulação do capital. Assim, a luta no campo das políticas sociais, longe de ser meramente reformista ou politicista, pode representar, em sua radicalidade, aquilo que Oliveira considerou como uma "vigorosa crítica ao valor feita no plano da política" (2001, p. 95). Vejamos essas questões de forma um pouco mais detalhada. 


\section{Distribuição da renda nacional, repartição do valor e fundo público}

Nos capítulos finais de O capital, livro terceiro, Marx (1986b) explicita que a distribuição tem sua origem no processo de produção determinado histórica e socialmente, conformando a totalidade do processo de produção e reprodução da vida social.

Conforme destaca Marx (1986b, p. 286), considerando o produto anual de uma nação, constituído por todo o capital investido naquele período determinado, ou seja, o capital constante, o capital variável e a mais-valia, se descontarmos o valor relativo à reposição do capital constante utilizado para a produção, o que resta refere-se à renda/receita bruta ou renda/receita nacional, ou seja, a distribuição básica da sociedade expressa em capital variável/ salário e mais-valia que formam o valor novo produzido no referido ano.

Nessa divisão da renda nacional ocorre o conflito central entre as classes sociais antagônicas do capitalismo: a luta do trabalho para ampliar o valor do trabalho necessário, reduzindo, por conseguinte, o valor relacionado ao trabalho excedente e, ao contrário, a luta do capital para ampliar a mais-valia, reduzindo o valor do trabalho necessário. O resultado dessa luta de classes determina a distribuição da renda nacional.

Estabelecida tal demarcação da renda nacional, no campo capitalista ocorre uma luta entre as diferentes frações de classe acerca da repartição da mais-valia. Vejamos, então, os elementos constitutivos dessa disputa.

De acordo com Marx (1986b, p. 281), a renda fundiária vai delimitar o quantum de mais-valia estará disponível para a constituição do lucro médio. "Por isso, lucro médio mais renda são iguais à mais-valia."

Assim, os proprietários de terra, bem como os proprietários de espaços físicos onde se realiza a produção, se apresentam como rentistas que disputarão uma fração da mais-valia para sua acumulação.

Por outra parte, convém lembrar que a propriedade do capital monetário acessa também a mais-valia. Dessa forma, a soma do lucro empresarial mais o juro possui como limite de grandeza o lucro médio que será 
disputado entre essas duas frações do capital (capital empresarial e capital monetário). A função do capital monetário é proporcionar adiantamento de capital para efetivação da produção. Devido a essa função, ele se credencia a se apropriar de uma parcela da mais-valia a partir da disputa de uma fração do lucro médio.

Segundo Marx (1986a), não há determinação objetiva que defina o quantum do lucro médio será destinado a uma ou outra fração. Isso se define pela relação de concorrência e oferta e procura.

Do ponto de vista da luta intercapitalista, devemos ainda incorporar o lucro comercial, que está embutido no lucro médio existente e refere-se a uma cota-parte produzida pelo capital industrial que tem como função viabilizar a realização da mais-valia. Ou seja, em termos gerais, quando Marx trata do lucro empresarial, no contexto do debate sobre o capital portador de juros, inclui a cota-parte do capital industrial e do capital comercial.

O capital comercial, ao se autonomizar do processo de produção, enquanto responsável por uma atividade em si, a realização do valor, no quadro da divisão social do trabalho se apresenta como uma força que tensionará o lucro industrial. Nesse sentido, Marx deixa claro que o capital comercial participa do lucro sem participar de sua produção. O capital comercial, assim como o capital monetário e a renda fundiária, disputará uma fração da mais-valia produzida pelo capital industrial. Em outros termos, cabe frisar que o único capital que produz mais-valia é o industrial; os demais capitais e a renda fundiária disputam a mais-valia produzida na esfera da produção, realizando a sua repartição entre os diferentes capitais.

A taxa média de lucro é calculada levando em consideração a totalidade da mais-valia produzida em relação ao capital total investido na produção mais o montante de capital comercial existente. Nas palavras de Marx (1986a, p. 216), "esse lucro médio é agora determinado de outro modo. É determinado [...] sobre o capital produtivo total + capital comercial, de tal modo que, se há 900 de capital produtivo e 100 de capital comercial, a taxa média de lucro é $=180 / 1000=18 \%$ ". 
O lucro comercial é constituído, assim, no processo de definição do lucro médio. Portanto, o capital comercial participa da formação da taxa média de lucro.

Por fim, cabe pontuar brevemente a luta intercapitalista entre as diferentes frações do capital industrial (ramos de produção) e entre os seus capitais individuais em torno da mais-valia produzida.

A base material sobre a qual se dá essa disputa situa-se na formação do preço de produção que possui como diferencial a produtividade de cada ramo e/ou de cada capital em particular. Desta forma, o capital mais produtivo se apropria de um valor acima da mais-valia que produz ao se apropriar de parte da mais-valia produzida por um capital menos produtivo. Assim como um ramo da produção mais produtivo se apropria da mais-valia de um ramo menos produtivo. Esses processos são operados tendo como mediação o superlucro presente na formação da taxa média de lucro e/ou nas condições que certas esferas da produção possuem no sentido de atuar para "evitar a transformação dos valores de suas mercadorias em preços de produção e, por conseguinte, a redução de seus lucros ao lucro médio" (Marx, 1986a, p. 152).

Portanto, a disputa intercapitalista também se expressa no próprio locus da produção de mais-valia, seja entre os capitais individuais de um mesmo ramo da produção, seja entre os diferentes ramos.

Recuperando todo o processo anterior, a mais-valia produzida socialmente é disputada por diferentes capitais: capitais individuais e entre ramos da produção (disputas na esfera do capital industrial), capital comercial, capital monetário e rentistas. A mais-valia global pode ser definida como o somatório da renda fundiária mais o lucro industrial, mais o lucro comercial, mais juro. Esse quadro, portanto, apresenta a disputa em torno da mais-valia pelas diferentes frações do capital, a partir da distribuição inicial da renda nacional.

O movimento geral implica, no campo da distribuição da renda nacional, a disputa da riqueza produzida entre as classes fundamentais (capital e trabalho) e, em outra dimensão do processo, no campo da repartição, a disputa efetivada em torno da mais-valia pelas diferentes frações do capital, configurando a luta intercapitalista da e na sociedade burguesa. 
Entretanto, com a expansão da intervenção do Estado na sociedade, esse processo de disputa da riqueza socialmente produzida ganha um contorno qualitativamente diferenciado devido à consequente expansão do fundo público. Tal disputa travada na sociedade entre as classes e frações de classes pela riqueza produzida passa agora a ocorrer também na esfera estatal em torno do fundo público, principalmente em dois momentos fundamentais: na definição da tributação e na definição do gasto público. Qualitativamente falando, essa disputa busca, de alguma forma, compensar as perdas ou ampliar os ganhos conquistados no âmbito da luta social entre as diferentes classes e frações de classes, realizada em torno da riqueza produzida.

O fundo público, dessa maneira, se expressa como mais um espaço público da luta social. A defesa de uma tributação progressiva ou regressiva recoloca a disputa entre as classes fundamentais do capitalismo no âmbito estatal de forma significativa. Por outro lado, a definição dos gastos públicos entre aqueles voltados para a ampliação do salário indireto e aqueles destinados à reprodução do capital expressam o mesmo conflito de interesses, porém processado na área da execução dos recursos públicos. Se tal dinâmica descreve, em termos gerais, a luta entre as classes fundamentais na esfera estatal, ela não esgota os conflitos existentes, pois, do ponto de vista do capital, as diferentes frações buscarão, por um lado, independente do resultado da disputa entre as classes fundamentais, reduzir sua participação na ponta da tributação e ampliá-la no lado oposto, na dimensão relativa ao gasto público.

Diferentemente do apontado por Marx, em pelo menos duas passagens do livro terceiro (Marx, 1986a, p. 39 e 141), os impostos, enquanto constituintes do fundo público, devem ser analisados não só como uma das partes em que a mais-valia é repartida, mas como um novo momento que afeta tanto a distribuição da renda nacional entre capital e trabalho, quanto a repartição da mais-valia entre as diferentes frações do capital. A equação, no entanto, só se completa se agregarmos a distribuição do gasto público na análise, buscando, assim, desvelar, de forma conclusiva, a partir da mediação do fundo público, a distribuição da renda e a repartição da mais-valia que finalmente ocorre na sociedade em determinado período histórico. Dessa 
forma, o componente político da luta de classes interfere no processo de distribuição e repartição da riqueza a partir das bases materiais estabelecidas pelas dinâmicas relacionadas à definição do valor da força de trabalho e da mais-valia, a qual será a base de definição do processo de repartição do valor.

A partir do traçado desse quadro teórico, tendo como fundamento a distribuição da renda nacional e a repartição da mais-valia no contexto da lógica geral da acumulação capitalista, podemos agora aprofundar a análise dessa dinâmica para a particularidade do capitalismo em sua fase monopólica, explorando a intervenção do Estado via mediação do fundo público.

\section{Fundo público e políticas sociais: questões teóricas}

Entendemos que a categoria "fundo público", conforme desenvolveremos abaixo, permite, de forma mais consistente, analisar o processo de produção e reprodução das relações sociais no quadro do capitalismo monopolista, em especial a partir da dinâmica do "capitalismo tardio", articulando a dimensão econômica da distribuição e da repartição da mais-valia, com sua expressão política que se manifesta tanto no campo da sociedade civil — nas lutas entre as classes e suas frações em torno da distribuição da riqueza entre mais-valia e salário direto e da repartição da mais-valia através da luta intercapitalista - , quanto na esfera estatal, através, principalmente, das lutas políticas no campo da tributação e da definição do gasto público, tendo como objetivo central interferir na constituição e na dinâmica da execução do fundo público.

Tal adequação se revela, sobremaneira, devido ao fato de o objeto de estudo proposto ser direcionado ao debate das políticas sociais.

Podemos indicar, sinteticamente, que as causas da expansão do fundo público, a partir da redefinição das funções do Estado, encontram-se nas necessidades de enfrentar a tendência à superacumulação, no contexto do capitalismo monopolista, aliada ao fortalecimento da influência política do movimento operário (Mandel, 1982). Ou seja, tanto as ações voltadas para 
garantir as condições gerais de produção, função precípua do Estado enquanto "capitalista total ideal" (Idem), quanto as estatais, destinadas às intervenções voltadas para a integração das classes dominadas, requerem recursos produzidos socialmente. Entretanto, as primeiras, de corte nitidamente econômico, constituem o eixo central da intervenção estatal, determinando, assim, o leque de possibilidades para as intervenções destinadas à área social.

O formato e o conteúdo das políticas sociais que serão implementadas dependerão da correlação de forças sociais existentes em cada sociedade em determinado contexto histórico. Portanto, o nível de organização da classe trabalhadora, mediada pelo grau de desenvolvimento de cada formação econômico-social, irá influenciar sobremaneira na constituição das políticas sociais e na configuração estatal que será estruturada (Netto, 1992). Mandel (1982, p. 338) destaca a ampliação da legislação social, vinculando-a, por um lado, à necessidade de salvaguardar a dominação do capital frente ao crescimento da "luta de classe do proletariado", e, por outro lado, visando garantir a reprodução geral capitalista, assegurando a reprodução física da força de trabalho. Nesse contexto, continua o autor, (p. 338-339), ocorre "uma redistribuição considerável do valor socialmente criado em favor do orçamento público, que tinha de absorver uma percentagem cada vez maior dos rendimentos sociais a fim de proporcionar uma base material adequada à escala ampliada do Estado do capital monopolista".

Nesses termos, podemos dizer que a mediação objetiva que estabelece a relação entre a orientação estatal da intervenção econômica e as bases materiais para a realização da política social é realizada através do fundo público.

Francisco de Oliveira (1998a, p. 19-20), em seu ensaio "O surgimento do antivalor", publicado pela primeira vez em 1988, indica que o padrão de financiamento público da economia capitalista, a partir dos anos 1940,

pode ser sintetizado na sistematização de uma esfera pública onde, a partir de regras universais e pactadas, o fundo público, em suas diversas formas, passou 
a ser o pressuposto do financiamento do capital, de um lado, e, de outro, do financiamento da reprodução da força de trabalho, atingindo globalmente toda a população por meio dos gastos sociais.

Diferentemente da fase concorrencial, segundo o autor, o fundo público no "capitalismo tardio" tornou-se um componente estrutural insubstituível da reprodução ampliada do capital e das condições de vida. Continuando a análise, Oliveira (1998a, p. 26), na mesma linha de Mandel, apesar de não utilizá-lo como referência, aponta que a dinâmica do Estado, nessa fase, amplia sua intervenção econômica e principalmente social para manter a apropriação privada da produção social.

A mediação do fundo público, a partir de sua expansão, impõe a necessidade de considerá-lo para pensar a dinâmica da acumulação e a relação existente entre tal dinâmica e seus impactos na tendência à queda da taxa de lucro. Isso porque o fundo público incide tanto na ponta do capital constante, via investimento em pesquisa de ponta, programas especiais, produção agrícola de determinados produtos, subsídios, entre outros, quanto na do capital variável, através do salário indireto. Nesse quadro, determinadas frações e setores de classes são beneficiados em detrimento de outros, influenciando decisivamente na taxa de lucro alcançada por um ou outro setor e nas condições de vida dos diferentes segmentos da classe trabalhadora (Oliveira, 1998a).

Mandel (1982, p. 339-340) aponta a expansão das intervenções do Estado no capitalismo tardio, na esfera das condições gerais de produção, como consequência da necessidade de "redução da rotação do capital fixo, aceleração da inovação tecnológica e o aumento enorme dos custos dos projetos de acumulação do capital devido à terceira revolução tecnológica". Diretamente, essa tendência se expressa na destinação dos recursos estatais para "financiar ou subsidiar usinas nucleares, aviões a jato, e grandes projetos industriais de todos os tipos". A ação indireta do Estado nessa área se efetiva através do "fornecimento de matérias-primas baratas mediante a nacionalização das indústrias particulares que a produzem, subvencionando, assim, de forma dissimulada, o setor privado". 
O processo de expansão do fundo público gerou, na interpretação de Oliveira (1998a), a constituição de uma esfera pública em torno do orçamento do Estado, produzindo mais um espaço onde se realiza a luta de classes. As disputas tanto no campo da arrecadação/tributação quanto na definição dos gastos públicos expressam as lutas entre as classes e frações de classes na sociedade. Obviamente, a existência dessas lutas não retira o caráter objetivo da necessidade estrutural do fundo público para a reprodução ampliada do capital no quadro do capitalismo monopolista. Contudo, as ações das classes nesse processo podem produzir, em determinadas conjunturas, uma "retração da base social da exploração". Nesse cenário, "a fração do trabalho não pago, fonte da mais-valia, se reduz socialmente" (Oliveira, 1998a, p. 26).

Entretanto, o artigo de 1988 escrito por Oliveira (1998a) apresenta um problema teórico, detectado por Behring (2008) e ratificado por Salvador (2010), na medida em que o autor caracteriza o fundo público somente como antivalor, ao tratar da relação entre este e o capital privado e, em seguida, indica que as antimercadorias sociais não têm como função extrair mais-valia e gerar lucro. ${ }^{2}$

Essa formulação do autor é alterada em 1993 (Oliveira, 1998b, p. 53) e, de forma mais clara, sintetiza sua tese:

O fundo público, portanto, busca explicar a constituição, a formação de uma nova sustentação da produção e da reprodução do valor, introduzindo, mixando, na mesma unidade, a forma valor e o antivalor, isto é, um valor que busca a mais-valia e o lucro, e uma outra fração, que chamo de antivalor, que busca não valorizar-se per se, pois não é capital, ao juntar-se ao capital, sustenta o processo de valorização do valor.

Com essa nova formulação, o autor esclarece que parte do fundo público é valor e que parte é o que ele considera antivalor, mas, ao mesmo tempo indica que a parcela antivalor também participa, embora não

2. Para conferir, ver a formulação de Oliveira (1998a, p. 29). 
diretamente como capital, do processo de valorização do valor. Portanto, a parte constitutiva do fundo público que participa indiretamente da acumulação, seja via aporte ao capital constante ou através da efetivação do salário indireto, atua na dinâmica da produção de valor, portanto, da extração da mais-valia e da geração de lucro, porém não como capital.

Aqui encontramos uma determinação central do que Oliveira considera antivalor. Ou seja, para o autor, o antivalor refere-se à fração do fundo público que, por não ser capital — pois não entra no processo comprando mercadorias, força de trabalho e meios de produção para produzir mais-valia - , gera uma contradição na dinâmica de produção e reprodução das relações sociais. Por isso, Oliveira (1998a, p. 53) utiliza a metáfora da física, que afirma que "o antivalor é uma partícula de carga oposta que, no movimento de colisão com a outra partícula, o valor, produz o átomo, isto é, o novo excedente social".

Behring (2008, p. 54) critica a tese do antivalor desenvolvida por Oliveira:

[...] parece contraditório não considerar o fundo público na reprodução geral do capital, através de subsídios [...] e de reprodução mesma da força de trabalho como fonte de criação de valor [...]. Dessa forma, consideramos que o fundo público não poderia ser considerado um antivalor, como pensa Oliveira, uma vez que o mesmo participa de forma direta e indireta do ciclo de produção e reprodução ampliada do valor.

Discordamos do argumento de Behring na medida em que vimos que o fato de determinada fração do fundo público ser caracterizado como antivalor não significa que essa fração não participe do processo de produção e reprodução do capital. O antivalor é a forma com que o fundo público contribui para a reprodução do capital e da força de trabalho, não atuando como capital per se, na medida em que não compra nem capital constante nem capital variável para produzir mais-valia. Assim, entendemos que o antivalor é a expressão da contradição do sistema. A punção da mais-valia e do salário realizada pelo fundo público através da tributação é a forma com que, 
a partir do valor, parte do fundo público se transforma em antivalor, o que não é o mesmo que o não valor, pois é apenas a tensão/contradição do sistema, mas não sua superação.

O que consideramos relevante para o trabalho aqui proposto diz respeito ao fato de que Oliveira (1998a e 1998b), ao se deter na dinâmica do fundo público, consegue teorizar, a partir de sua expansão na fase do capitalismo tardio, sua constituição como um mix de recursos que viabiliza diretamente a produção de valor (empresas estatais) e indiretamente, através de aportes do fundo público ao capital constante (subsídios para a produção, desenvolvimento da ciência e tecnologia, juros subsidiados...) e ao capital variável (políticas sociais — efetivação do salário indireto). Nesse sentido, ele mostra a relação dialética entre a dinâmica da acumulação capitalista e as políticas sociais via mediação do fundo público. Além disso, o autor destaca com propriedade a contradição de tal processo, indicando a possibilidade da "retração da base social da exploração" a partir da expansão do salário indireto. Em outras palavras, ele argumenta que o antivalor tensiona a dinâmica da valorização do valor, contribuindo para processos de construção de sociabilidade fundada no não valor. $\mathrm{O}$ antivalor se apresenta como possibilidade da negação do valor (Oliveira, 2001, p. 95-96). ${ }^{3}$

Nesse sentido, no limite, conforme destaca o autor, a ampliação da fração do antivalor destinada ao salário indireto pode gerar a queda da taxa de lucro. Ou seja, teoricamente, a implicação estaria no fato de que a queda não seria baseada na elevação da composição orgânica, mas sim na elevação do valor da força de trabalho em relação à mais-valia produzida. Essa possibilidade não é descartada por Marx, apesar de ser caracterizada como uma excepcionalidade (Marx, 1986a, p. 182).

Essa questão levantada por Oliveira encontra respaldo também nas reflexões de Mandel (1982). Segundo o economista belga, a expansão da intervenção do Estado produz novas contradições no sistema. Essa expansão,

3. Não é por acaso, conforme destaca Oliveira (2001), que as políticas econômicas neoliberais buscam repor a lei do valor em toda a sua plenitude, através da privatização e mercantilização absoluta, numa nítida investida antissocial. 
baseada na "redistribuição dos rendimentos sociais para o orçamento nacional, não pode levar a uma redução em longo prazo da taxa de mais-valia, ou ameaçar a valorização do capital: o orçamento ideal é aquele que gera um aumento da taxa de mais-valia e da taxa de lucros" (Idem, p. 342).

É óbvio que essa possibilidade não deve ser entendida como se fosse possível, na sociabilidade capitalista, ocorrer tal movimento sem reação do capital e como desenvolvimento linear para a transição socialista (Mandel, 1982, p. 339).

No entanto, o próprio Mandel (1982, p. 216 e 321) considera a possibilidade de elevação do valor da força de trabalho através dos gastos sociais. Essa possibilidade está relacionada à luta entre os operários, por um lado, e a classe burguesa e o Estado, por outro. O capital, assim, deve buscar evitar ou restringir as atividades das organizações dos trabalhadores que possam ameaçar seus interesses (Mandel, 1982, p. 168-169). A questão nos remete ao debate sobre as políticas sociais ou, nos termos de Oliveira (1998a), à relação entre o fundo público e a reprodução da força de trabalho.

As políticas sociais universalizadas podem se desenvolver no sentido da ampliação da participação do salário indireto no salário total. Essas políticas se constituem como antimercadorias sociais, pois não têm finalidade de gerar lucros, nem mediante sua ação dá-se a extração de mais-valia. Isto não significa dizer que não contribuem com o processo de valorização do valor, como mais bem explicitado por Oliveira (1998b) no texto de 1993. O processo indica a possibilidade teórica de ocorrer uma tendência à "des-mercantilização da força de trabalho" (Oliveira, 1998a, p. 30; Esping-Andersen, 1991).

Parafraseando Mandel (1982) em sua interpretação acerca dos esquemas de reprodução em Marx, podemos dizer que o "antivalor" que incide sobre a força de trabalho, nos termos de Oliveira (1998a e 1998b), é uma abstração metodológica realizada para provar a contradição constitutiva do fundo público, firmada, principalmente, pela relação entre os aportes de recursos à expansão do salário indireto e a dinâmica da acumulação capitalista, o que possibilita, consequentemente, provocar a "retração da base social da exploração" (Oliveira, 1998a, p. 26). 
Nesse sentido, entendemos que a contradição operada pelo antivalor está presente na realidade, apesar de a "retração da base social da exploração" não ser uma tendência do modo de produção capitalista, mesmo porque sua realização depende da luta de classes. No entanto, tal possibilidade pode ser perspectivada pela ampliação dos gastos sociais e pelo movimento neoliberal de redução dos referidos gastos. Nesse caso, essa determinação, apesar de não ser tendência, pode tensionar a lógica da acumulação. Por outro lado, o fato de ser contradição, e parece que não há dúvida em relação a isso, já daria consistência à tese de Oliveira.

Outra crítica presente refere-se ao fato de Oliveira (1998a, p. 27) afirmar que "o padrão de financiamento público 'implodiu' o valor como único pressuposto da reprodução ampliada do capital, desfazendo-o parcialmente enquanto medida da atividade econômica e da sociabilidade em geral".

Duas considerações merecem ser feitas. A primeira, na medida em que o verbo implodir está entre aspas, deve-se considerá-lo metaforicamente. A segunda questão a ser considerada refere-se ao entendimento de que o que "implodiu” foi o valor enquanto único pressuposto da valorização, ou seja, o valor em si não foi "implodido".

No que se refere a essa segunda consideração, Oliveira (1998a, p. 29) afirma que o valor continua sendo a categoria central e a práxis do sistema. A questão é que ele "não pode, agora, reportar-se apenas a si mesmo: ele tem que necessariamente reportar-se a outros componentes; no caso, o fundo público, sem o que ele perde a capacidade de proceder à sua própria valorização".

Entendemos que a questão central dos artigos de Oliveira (1998a e 1998b) é mostrar que o fundo público, enquanto constituido da fração que ele denomina de antivalor, amplia as contradições do sistema, na medida em que, por um lado, comporta-se como um anticapital na sua relação com o capital, no sentido que destrói o caráter autorreflexivo do valor. Ou seja, o valor tem que se reportar ao fundo público para viabilizar sua valorização devido à contradição existente entre afração do fundo público que não é valor e sua função de sustentação do capital. Por outro lado, a fração do 
antivalor destinada à reprodução da força de trabalho pode impactar a base social da exploração, restringindo-a.

Esse processo não elimina a vigência da lei do valor e nem sua centralidade sistêmica; apenas demonstra uma nova dimensão da contradição do modo de produção capitalista que passa a ocorrer na medida da expansão do fundo público.

Nesse sentido, o argumento do novo pressuposto (antivalor) parece válido, pois efetivamente é um excedente que não atua de forma direta no novo ciclo de produção de valor, mas passa pela mediação política do fundo público que reconfigura a repartição do valor e a distribuição da renda nacional. É essa mediação política que possibilita a produção de antimercadorias sociais e, portanto, possibilita a retração da base social da exploração.

\section{4. À guisa de conclusão: tendência do comportamento do fundo público na América Latina}

Como vimos anteriormente, o fundo público se materializa a partir de dois movimentos: o da arrecadação e o do gasto público.

Bresser-Pereira (1982), apesar de trabalhar numa concepção distinta da tratada neste artigo, desenvolve uma descrição extremamente útil para pensarmos o fundo público a partir do movimento de arrecadação e de gasto público no quadro do capitalismo tardio.

Do ponto de vista da despesa, Bresser-Pereira (1982) propõe uma classificação pautada em quatro itens: segurança e administração, consumo social (básico e de luxo), acumulação estatal e subsídios à acumulação privada. Dessa forma, o total do gasto público refere-se ao somatório dessas diferentes despesas.

Como as despesas do Estado beneficiam uma ou outra classe social, o autor infere que o salário total do trabalhador seria igual ao salário mais o consumo social básico. E a renda total das camadas média e alta e dos capitalistas seria o somatório dos salários dos tecnoburocratas mais o lucro, 
mais o consumo social de luxo, mais subsídios ao capital, mais segurança e administração do Estado (na medida em que essas despesas, ao manter a ordem social, "beneficiam principalmente as classes dominantes, ou seja, os capitalistas e a alta tecnoburocracia podem ser consideradas salários indiretos" (Bresser-Pereira, 1982, p. 21)).

A partir dessa formulação, Bresser-Pereira infere que as despesas do Estado possuem efeito distributivo ou concentrador, dependendo do quantum que será destinado ao salário indireto e à renda dos capitalistas e das camadas altas de tecnoburocratas em relação aos impostos arrecadados de cada classe e fração de classe.

Assim, considerando um orçamento equilibrado, se a diferença entre o consumo social básico e o imposto que incide sobre os trabalhadores for positivo, o orçamento terá uma tendência à distributividade. No entanto, caso seja positiva a diferença entre o consumo de luxo mais subsídios ao capital, mais segurança e administração do Estado e os impostos que incidem sobre os tecnoburocratas e os capitalistas, a tendência da estrutura do orçamento público será concentradora.

Assim, para que ocorra a "retração da base social da exploração", nos termos de Oliveira (1998a), será necessário que a tendência do fundo público se expresse na primeira hipótese. Ou seja, os gastos públicos voltados para o consumo social básico devem ser maiores que os impostos que incidem sobre a classe trabalhadora e, em contraparte, as despesas públicas voltadas para a segurança e administração, consumo de luxo e subsídios ao capital, devem ser menores que os impostos que incidem sobre o capital e a renda das camadas altas da tecnoburocracia, na mesma proporção da primeira diferença, em se tratando de um orçamento equilibrado.

No entanto, para analisar a possibilidade de efetivação desse cenário numa economia concreta, é fundamental entender, conforme sinalizado no início deste texto, a dinâmica de acumulação capitalista, o capitalismo dependente, o padrão de reprodução de capital, a política econômica implementada principalmente em relação aos seus impactos na tributação e na definição dos gastos públicos e na estrutura institucional que efetiva as políticas sociais. 
Considerando que a dinâmica da dependência na América Latina baseada na superexploração da força de trabalho como forma de compensar a transferência de valor para viabilizar a acumulação interna do capital produz a baixa condição de vida da classe trabalhadora, gerando aumento das necessidades para sua reprodução social e, simultaneamente, restringe o quantum de recursos do fundo público possível para o desenvolvimento de políticas sociais - na medida da necessidade de o Estado atuar para compensar a transferência de valor para os países centrais -, sugerimos como hipótese que a consequência desse processo conforma as determinações objetivas centrais que fundamentam a tendência concentradora do fundo público nos países periféricos. Nessas condições, o antivalor possui baixa potência para processar uma contradição significativa à fração do valor constitutiva do fundo público e ao processo de produção de valor.

Tal fato nos parece determinante, do ponto de vista objetivo, para compreender a conformação das políticas sociais dos países dependentes que não se desenvolveram enquanto políticas universalistas, públicas e gratuitas de responsabilidade do Estado e de direito de cidadania. No entanto, os fundamentos desta hipótese devem ser verificados em futuras pesquisas.

\section{Recebido em: 20/1/2016 - Aprovado em: 25/2/2016}

\section{Referências bibliográficas}

BEHRING, E. Acumulação capitalista, fundo público e política social. In: BOSCHETTI, I. et al. (Orgs.). Política social no capitalismo: tendências contemporâneas. São Paulo: Cortez, 2008.

. Rotação do capital e crise: fundamentos para compreender o fundo público e a política social. In: et al. (Orgs.). Financeirização, fundo público e política social. São Paulo: Cortez, 2012. 
BRESSER-PEREIRA, L. C. Despesas do Estado, repartição e valor. Revista de Economia Política, São Paulo, v. 2/3, 1982.

ESPING-ANDERSEN, G. As três economias políticas do Welfare State. Lua Nova, revista de cultura e política, São Paulo, n. 24, 1991.

MANDEL, E. O capitalismo tardio. São Paulo: Abril Cultural, 1982.

MARINI, R. M. Sobre el patrón de reproducción de capital en Chile. Cuadernos CIDAMO, México, n. 7, 1982.

. Dialética da dependência. In: TRASPADINI, R.; STEDILE, J. P. (Orgs.). Ruy Mauro Marini: vida e obra. São Paulo: Expressão Popular, 2005.

. O ciclo do capital na economia dependente. In: FERREIRA, C.; OSÓRIO, J.; LUCE, M. S. (Orgs.). Padrão de reprodução do capital. São Paulo: Boitempo, 2012.

MARX, K. O capital: crítica da economia política. São Paulo: Nova Cultural, 1986a. Livro III, t. I.

. O capital: crítica da economia política. São Paulo: Nova Cultural, $1986 b$. Livro III, t. II.

NETTO, J. P. Capitalismo monopolista e Serviço Social. São Paulo: Cortez, 1992.

OLIVEIRA, F. O surgimento do antivalor. In: Os direitos do antivalor: a economia política da hegemonia imperfeita. Petrópolis: Vozes, 1998a.

. A economia política da social-democracia. In: Os direitos do antivalor: a economia política da hegemonia imperfeita. Petrópolis: Vozes, 1998 b.

. Nós que combatíamos tanto: a economia política da cidadania. Revista da Sociedade Brasileira de Economia Política, Rio de Janeiro, 2001.

OSÓRIO, J. Explotación redoblada y actualidad de la revolución: refundación societal, rearticulación popular y nuevo autoritarismo. Mexico: Editorial Itaca, 2009.

. América Latina: o novo padrão exportador de especialização produtiva: estudo de cinco economias da região. In: FERREIRA, C.; OSÓRIO, J.; LUCE, M. S. (Orgs.). Padrão de reprodução do capital. São Paulo: Boitempo, 2012.

SALVADOR, Evilásio. Fundo público e seguridade social no Brasil. São Paulo: Cortez, 2010 . 